\title{
РОЛЬ ДИСТРИБУТИВНОГО АНАЛИЗА ПРИ ВЫЯВЛЕНИИ СПЕЦИФИКИ ЭКСТЕНСИОНАЛА ЯЗЫКОВОГО ЗНАКА (НА МАТЕРИАЛЕ ЛЕКСЕМЫ VIEW)
}

(C) Эльвира Шарифуллина

\section{THE ROLE OF DISTRIBUTIVE ANALYSIS IN IDENTIFYING THE SPECIFICS OF THE LANGUAGE SIGN EXTENSION (BASED ON THE LEXEME VIEW)}

\section{Elvira Sharifullina}

\begin{abstract}
The article presents an algorithm and results of an intralingual comparative study of the English word view semantics. Objectification and differentiation of individual lexical-semantic variants of this lexeme are based on publicistic, fictional and academic texts from the Corpus of Contemporary American. In the course of our study, we used the definitional analysis and the distributional method. The total size of the subcorpus, compiled for the current study, amounts to 112667 lexemes. In the framework of the corpus approach, the semantic structure of the word view is modeled in accordance with the following algorithm: (1) identification of the word on the basis of etymological and explanatory dictionaries, (2) lexical and semantic analysis, (3) confirmation of the existence of individual lexical and semantic variants, recorded in lexicographic sources in the texts of a particular genre (type, discourse), (4) modeling the semantic structure of separate meanings of the word, (5) modeling the intra-system relations of the word view with other words. In the local context, the research confirmed significant differences in the functions of separate meanings of the word in the texts of academic and publicistic discourse as well as in fiction. The analysis of local syntactic and lexical contexts enabled us to distinguish three main meanings in the semantic structure of the word view.
\end{abstract}

Keywords: semantics, Corpus of Contemporary American English, definitional analysis, distributional method, corpus, corpus approach, semantic structure modeling.

В статье предложены алгоритм и результаты внутриязыкового сопоставительного исследования семантики английского слова view. Объективация и дифференциация отдельных лексикосемантических вариантов данной лексемы осуществлена на материале корпуса СОСА с привлечением публицистических, художественных и академических (научных и учебных) текстов при помощи дефиниционного анализа и дистрибутивного метода. Общий объем корпуса изученных текстов составил 112667 словоупотреблений. В рамках корпусного подхода моделирование семантической структуры слова view осуществлено в соответствии со следующим алгоритмом: (1) отождествление слова на базе этимологических и толковых словарей, (2) лексико-семантический анализ и (3) подтверждение существования отдельных лексико-семантических вариантов, зафиксированных в лексикографических источниках, в текстах изучаемого жанра (типа текста, дискурса), (4) моделирование компонентного состава лексико-семантических вариантов, (5) моделирование внутрисистемных отношений изучаемого знака с другими языковыми знаками. Осуществленное исследование подтвердило наличие существенных различий в локальных контекстах при функционировании отдельных ЛСВ данного языкового знака в текстах научного, публицистического и художественного дискурсов. Анализ локального синтаксического и лексического контекстов позволил выделить в семантической структуре изучаемого имени существительного три основных лексико-семантических варианта.

Ключевые слова: семантика, СОСА, дефиниционный анализ, дистрибутивный метод, корпус, корпусный подход, моделирование семантической структуры.

Современная языковедческая парадигма рассматривает все языковые знаки как особые формы хранения опыта и знаний, обретенных этносом и / или нацией о мире, себе, окружающей действительности. Языковая картина мира, в которой общество говорящих на дан- 
ном языке личностей вербализует свои представления о мире, по сути, является «зеркалом», отражающим специфику восприятия мира определенным языковым коллективом. Данная особенность весьма заметна при контрастировании ограниченных фрагментов языкового пространства. Использование языкового знака в дискурсе, то есть следование конвенциям исторического этапа развития языкового коллектива, выполняет функцию демонстрации своей принадлежности к (со)обществу. «Само качество, которое определяется как различие по отношению к экзогенной общественной макросистеме, связывает людей в эндогенную микросистему и даёт им чувство единства, сообщества, и безопасности» [Marshall, с. 39-40]. При этом лингвистическое «окружение» языкового знака, то есть его контекст, выступает как связующее звено с внешней ситуацией использования языкового знака. Ценность контекстов функционирования языковой единицы состоит в том, что именно в них зарождаются как потенциальные смыслы, так и направление развития семантики слова. Очевидно, что количество отдельных контекстов использования языковой единицы невозможно подсчитать, однако их классификация и «обобщение в обозримое число типичных ситуаций» вполне реальны [Электронный каталог периодических изданий НБ ТНУ, с. 197].

В современной когнитивно-дискурсивной парадигме языкознания синтез семантической структуры и упорядочение лексикосемантических вариантов (далее ЛСВ) языковых единиц признаются завершенными только при обеспечении достаточных контекстов употребления ЛСВ в дискурсе. При этом правила фиксации контекста диктуют использование как можно более широкого спектра жанров и типов текстов, в которых используется данная языковая единица. В случае многозначных единиц иллюстрации функционирования рассматриваются как основное средство выявления отдельных ЛСВ ее. Как в рамках внутриязыкового, так и межъязыкового сопоставительного подходов алгоритм исследования семантики слова предполагает синтез компонентного состава его отдельных ЛСВ. Наиболее результативным при этом признается дистрибутивный метод, при помощи которого (1) объективируется, каким образом «распределяются (встречаются и сочетаются) в речевом потоке (письменном тексте) относительно одна другой языковые единицы» [Там же, с. 198], на основе которого (2) наводятся семы и определяется семный состав от- дельных лексико-семантических вариантов слова [Стернин, Саломатина].

Термин «дистрибуция» трактуется в работе как «распределение языковых единиц, сочетания фонем, морфем, слов, допускаемые законами данного языка [Ефремова, с. 105], а алгоритм применения дистрибутивного метода предполагает фиксацию и учет связей языковых единиц, то есть их «со-встречаемости» в тексте. Мы исходим из положения о том, что каждый ЛСВ слова имеет свою уникальную дистрибуцию, то есть сочетаемость с другими словами, которая позволяет отделять один ЛСВ от другого. При этом сама способность к сочетаемости двух слов определяется наличием в их семантике логических и / или ассоциативных связей. Их отсутствие делает сочетаемость двух (и более) слов невозможной.

Динамика развития семантики большей части слов в языке - это длительный процесс семантических изменений, суть которых состоит в том, что «употребление слова в устойчивых сочетаниях может вести к утрате им тех определений (в широком смысле слова), которые обычны для него в данном контексте или в данной речевой ситуации» [Шмелев, с. 112]. При этом одна и та же форма может обретать новые семантические оттенки, а позднее - смыслы и ЛСВ. Именно эти семантические оттенки, в свою очередь, будут менять контекст языкового знака в дискурсе. Как писал В. Виноградов, «когда затронут один член цепи, откликается и звучит целое» [Виноградов, с 17]. Потенциальная возможность одной формы обретать новые значения определяется существующим в языке противоречием между предельностью памяти языковой личности и «непредельностью» референтов окружающего мира, при котором одни и те же языковые формы используются в различных коммуникативных ситуациях. Основным способом, разрешающим данное противоречие, является контекст, который, присутствуя в любом акте коммуникации, позволяет точно определить, какой из ЛСВ многозначного слова используется. Таким образом, «контекст является компенсирующим противовесом полисемии и поддерживает точный баланс многозначности и однозначности через контекстные условия» [Ольшанский, Скиба, с. 38].

Контекст определяется в отечественной парадигме как «совокупность формально фиксированных условий, при которых однозначно выявляется содержание какой-либо языковой единицы <..>, при этом под однозначностью следует понимать проявление в заданных условиях только одного конкретного содержания языковой формы...» [Колшанский, с. 47]. Таким образом, 
контекст выполняет три основные функции: нейтрализация (снятие) полисемии, сохранение и развитие полисемии, а при взаимодействии с полисемичным словом контекст выполняет функцию идентификатора ЛСВ [Ольшанский, с. 68]. Методика уточнения семного состава многозначного слова предполагает использование контекста таким образом, что он организует исходное значение слова, структурируя его в «позиционные варианты», в каждом из которых контекст реализует заключенные в слове семемы. Контекст позволяет осуществить отбор нужного в данной ситуации значения и его актуализацию. Актуализация, в свою очередь, является возможной, поскольку при отборе само значение уже выделено, а актуализация многозначного слова предполагает «приспособление его широкого толкования в языке для речи с помощью речи» [Кацнельсон, с. 54].

В рамках корпусного подхода для выявления структуры значения слова с применением дистрибутивно-статистического метода, разработанного в отечественной лингвистике [Супрун, Плотников, Аладко], предполагается последова- тельное осуществление ряда этапов. Причем метод может быть реализован в двух вариантах: упрощенном и полном.

Продемонстрируем направление и специфику реализации упрощенного варианта данного метода для моделирования семантической структуры многозначного слова английского языка view, включающего три основных шага.

1) Количественный анализ «встречаемости» слова в корпусе. В представленном исследовании был использован Корпус современного американского варианта английского языка COCA [COCA], в котором зарегистрировано 101363 вхождений слова view;

2) Статистический анализ сочетаемости изучаемого слова во всех синтаксических моделях, в которых данное слово может быть использовано. Имя существительное view используется в нескольких синтаксических моделях: V (mod) $\mathrm{N}, \mathrm{V}$ prep (mod) $\mathrm{N}$ и (mod) Adj $\mathrm{N}^{1}$. При этом синтаксическая модель (mod) Adj $\mathrm{N}$ зафиксирована в COCA 38501 раз с 5777 различными прилагательными в диапазоне частотности от different (1269 текстов) до threesixty (1 текст) (см. рис.1).

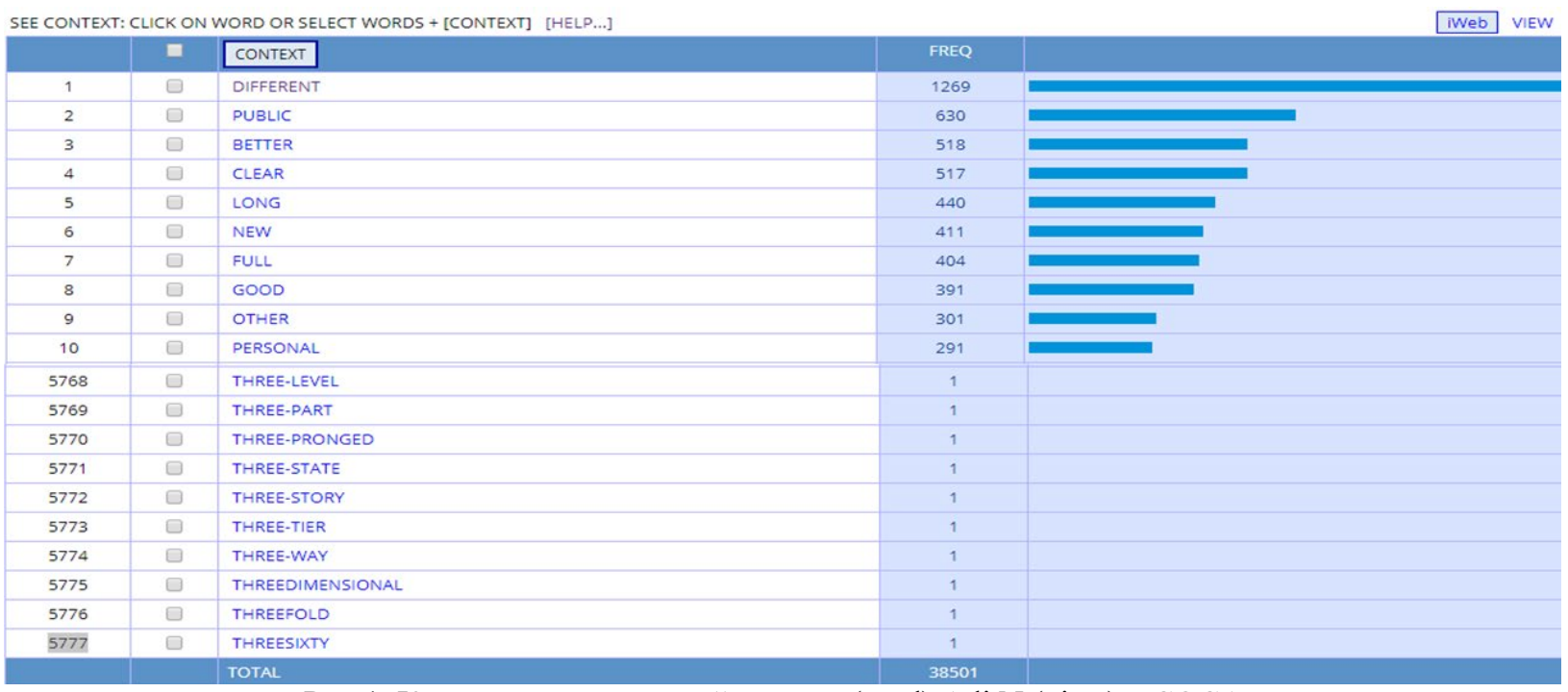

Рис.1. Количество вхождений модели (mod) Adj N (view) в COCA.

3) Статистический анализ совместной встречаемости отдельных лексем. Например, сочетание (mod) good view зафиксировано в COCA 307 раз и может реализовываться в сочетаниях со следующими модификаторами: a good view, the good view, my first good view, a really good view, a pretty good view, a

\footnotetext{
${ }^{1}$ (mod) Adj N: сокращение mod используется в значении modifier, модификатор, обычно артикль, наречие, местоимение, существительное или прилагательное, $\mathrm{Adj}$ - имя прилагательное, $\mathrm{N}$ - имя существительное.
}

fairly good view, a real good view, a damned good view, an extra good view, a very good view (см. рис. 2). Такого рода список модификаторов в пре- (левое окно) и постпозиции (правое окно) изучаемой лексемы именуем референтным списком модификаторов изучаемой синтаксической модели. 


\begin{tabular}{|c|c|c|c|}
\hline 1 & $\square$ & $\begin{array}{l}\text { COCA:2000:MAG } \\
\text { BoysLLfe }\end{array}$ & a special feeding feature in front of the lens lets you get an extra good view. $\$ 30$. Uncle Milton Industries Inc. 818-707-0800 www.unclemilton.com Handy Wo \\
\hline 2 & $\square$ & $\begin{array}{l}\text { COCA:1995:MAG } \\
\text { Astronomy }\end{array}$ & in the state. It was at Vekol Ranch that I had my first good view of Halley's Comet in 1986 as it was passing through Sagittarius on a cool \\
\hline 3 & $\square$ & $\begin{array}{l}\text { COCA:1998:FIC } \\
\text { ChicagoRev }\end{array}$ & left hip, the side of his long thigh, I have a very good view, too good, and I tell myself not to keep staring, not to \\
\hline 4 & $\square$ & $\begin{array}{l}\text { COCA:2005:FIC } \\
\text { MichiganQRev }\end{array}$ & jostling her and making her lose track of Hugh. " Quit hogging the good view. " the woman said. "I drove all the way from Pueblo and \\
\hline 5 & $\square$ & $\begin{array}{l}\text { COCA:2014:SPOK } \\
\text { CNN: Anthony Bourdain }\end{array}$ & , maybe a quarter of a mile wide. I've got a pretty good view from up here. BOURDAIN\# Yes. How many people worked here at its peak \\
\hline 6 & $\square$ & $\begin{array}{l}\text { COCA:1992: FIC } \\
\text { Mov:JenniferEight }\end{array}$ & a lecherous looking old bastard and Helena's dress rides up for a damned good view of the lingerie. \# FLESHY vOICE \# Happy Christmas, Max... \# MAX \# \\
\hline 7 & $\square$ & $\begin{array}{l}\text { COCA:2005:SPOK } \\
\text { CNN_Event }\end{array}$ & . So I think we can come out of this hearing with a fairly good view. I'm not sure of that, but we'll certainly try BLITZER Senator \\
\hline 8 & $\square$ & $\begin{array}{l}\text { COCA:1999:FIC } \\
\text { Analog }\end{array}$ & are, Cap'n Howe. In just a moment we'll have a pretty good view of them. " He sniffed loudly in passable imitation of Glaxia Fortinay. " \\
\hline 9 & $\square$ & $\begin{array}{l}\text { COCA:2006:FIC } \\
\text { Bk:PrometheusProject }\end{array}$ & was worse than usual. So I wasn't able to get a really good view of the group of men emerging from the HQ Quonset, including the elderly guy-or \\
\hline 10 & $\square$ & $\begin{array}{l}\text { COCA:1993:MAG } \\
\text { Astronomy }\end{array}$ & reasonably close to each other at the time, so terrestrial observers had a good view of the Red Planet. As late summer advanced in the southern hemisphere \\
\hline
\end{tabular}

Рис. 2. Совместная встречаемость отдельных лексем в модели (mod) Adj N (view)

Данный этап считается завершенным после выявления всех существующих (зафиксированных в корпусе) моделей и создания референтных списков контекстов данных моделей.

Современные классификации контекста многообразны, но все они выделяют языковой (собственно лингвистический) и внеязыковой (экстралингвистический) контексты. Экстралингвистический контекст в современной лингвистике трактуется как «ситуация коммуникации, включающая условия общения, предметный ряд, время и место коммуникации, самих коммуникантов, их отношения друг к другу и т. п.» [Ярцева, c. 238]. Лингвистический контекст есть «фрагмент текста, включающий избранную для анализа единицу, необходимый и достаточный для определения значения этой единицы» [Там же]. В отечественной и зарубежной парадигмах лингвистические контексты принято также классифицировать по типам (например, лексический, грамматический и т. п.) и объему. С точки зрения объема само понятие «контекст» предполагает деление на микроконтекст (контекст в объеме одного предложения), макроконтекст (контекст в объеме абзаца) и ситуационный (тематический) контекст (в объеме главы или целого произведения), хотя в некоторых классификациях и имеются определенные разногласия относительно выделяемых объемов контекста, когда различаются лишь микро- и макроконтекст [Арсеньева, Строева, Хазанович, с. 13]. Важно заметить, что разные виды и объемы лингвистического контекста позволяют наблюдать различные языковые явления. Для лексемы view в большинстве случаев достижение однозначного понимания и, соответственно, разграничение лексико-семантических вариантов возможно уже при наличии микроконтекста, то есть контекста одного предложения. Например:
$\mathbf{K A 2 3 6 3}^{2}$ - An instant later, the light flicked off, and her father vanished from view (здесь и далее разрядка наша - Э. Ш.) - букв.: 'Мгновение спустя свет погас, и ее отеи исчез из поля зрения, ${ }^{3}$. ЛСВ 1- «способность видеть что-либо или быть увиденным из определенного места» [Oxford English Dictionary] (далее - OED).

KA2077-Heglanced at the view of the church. - букв.: 'Он взглянул на церковь'. ЛСВ 2 - «вид или перспектива, как правило, привлекательного пейзажа, который может быть наблюдаем из определенного места» [Там же].

KA2746 - My "stand" was that, although I wholeheartedly agreed with his views about the desirability both of democracy and socialism, I was not sure Iraq and the Iraqi people were "mature for democracy". - букв.: 'Моя «позииия» заключалась в том, что, хотя я искренне соглашался с его мнением о желательности, как демократии, так и соииализма, я не был уверен, что Ирак и иракский народ "созрели для демократии»'. ЛСВ 3 - «особый способ рассмотрения или отношения к чему-либо; позиция или мнение» [Там же].

Полный алгоритм описания семантики языкового знака в современной лингвистической парадигме предполагает ряд последовательных действий: 1. Отождествление слова, то есть выделение всех употреблений единицы (одной материальной формы). 2. Выделение и составление

\footnotetext{
2 Аббревиатура КА обозначает «Подкорпус современного американского английского», составленный на основе The Corpus of Contemporary American English, COCA, специально для исследования, насчитывающий 112667 словоупотреблений. Четырехзначный номер после аббревиатуры - 2363 - обозначает номер предложения в авторском подкорпусе исследования.

${ }^{3}$ Перевод толкования значения слова и иллюстраций на русский язык здесь и далее осуществлен автором.
} 
перечня значений и ЛСВ изучаемой материальной формы. 3. Эпидигматический (лексикосемантический) анализ всех выявленных значений, в рамках которого необходимо установить наличие связей между выделенными значениями / ЛСВ. Данный этап осуществляется исключительно в синхронном срезе языка и завершается формированием модели семантической структуры слова. 4. Анализ компонентного состава отдельного значения или ЛСВ, в рамках которого выделяют грамматический, денотативный, коннотативный и фукционально-стилистический макрокомпоненты значения. На данном этапе осуществляется моделирование структуры значения. 5. Изучение системных отношений значения данного знака с другими знаками включает построение микросистем (гиперо-гипонимические, синонимические, антонимические и др.).

Рассмотрим каждый из этапов детально на примере слова view.

1. Отождествление слова. Лексема view по данным этимологических словарей появилась в английском языке в среднеанглийский период как заимствование из нормандского vieue (причастие прошедшего времени женского рода) от глагола veoir 'видеть', происхождение которого связывают с латинским videre, появившимся в начале 16 века [Там же].

2. Выделение и составление перечня значений и ЛСВ осуществлено в существующих словарях английского языка. Слово view, фиксируемое рядом академических словарей, функционирует в английском языке как имя существительное и глагол [Cambridge Advanced Learner's Dictionary and Thesaurus], [Collins English Dictionary], [OED].

View, сущ: 1. способность видеть что-либо или быть увиденным из определенного места. Например, "the end of the tunnel came into view" ' $B$ поле зрения появился конеи тоннеля'. 1.2. Осмотр предметов для продажи потенциальными покупателями, особенно произведений искусства на выставке; 2. вид или перспектива, как правило, привлекательного пейзажа, который может быть наблюдаем из определенного места. Например, "a fine view of the castle" - 'Прекрасныи вид замка'; 2.1. произведение искусства с изображением пейзажа. "Matisse's view of Collioure”- 'Картина Матисса «Вид Коллиура»'; 2.2. вид или фотография объекта с определенной точки, под определенным углом зрения. Е. g. " $a n$ aerial view of the military earthworks"; - "вид военных земляных сооружений с неба'; 3. особый способ рассмотрения или отношения к чемулибо; позиция или мнение. Например, "strong po- litical views"- 'сильные политические взгляды' [OED].

View, гл.: 1. осматривать, смотреть. Например, "the public can view the famous hall with its unique staircase"- 'Публика может осмотреть знаменитый зал с уникальной лестницей'; 1.1. изучать (дом или другое имущество) с целью возможной покупки или аренды. Например, "prospective buyers are requested to make an appointment to view the house"- 'Потенциальных покупателей просят договориться о встрече, чтобы изучить дом'; 1.2. смотреть (что-то) по телевизору. Например, "some people record the programme and view it later on their VCR" - 'Heкоторые люди записывают программу и смотрят ее позже на своем видеомагнитофоне'; 2. рассматривать в определённом свете, оценивать, судить. "Farmers are viewing the rise in rabbit numbers with concern" - 'Фермеры с беспокойством наблюдают за ростом численности кроликов'. Синонимы: consider, regard, look on, see, perceive, judge, adjudge, estimate deem, reckon, think of, treat [Там же].

Очевидно, что одна и та же форма, употребляемая в качестве глагола и имени существительного, имеет достаточно четкие дистрибутивные различия. Например, СОСА за период 19902017 гг. регистрирует 14375 контекстов view (гл.) и 84519 контекстов vi ew (сущ.). Показательны также различия избирательности данной лексемы относительно типа дискурса: в текстах художественной литературы за период 19902017 гг. СОСА фиксирует 11171 использование существительного view, в то время как в академическом (научные и учебные тексты) дискурсе то же существительное имеет частотность, более чем в два раза превосходящую, - 25062 вхождения. Различия частотности функционирования глагола в различных дискурсах также весьма существенны: в текстах художественной литературы - 810 использований, а в академическом дискурсе - 5245 фиксаций. Дистрибуция во всех случаях служит показателем и «разделителем» терминологического и художественного использования слова. Так, со словом view в англоязычных художественных текстах COCА зафиксировано 8979 различных форм глаголов, тогда как в сочетании с этим же словом в научных текстах зарегистрировано значительно больше глаголов $-30236$.

3. Эпидигматический (лексико-семантический) анализ предполагает выделение лексической и синтаксической дистрибуций лексемы, референтных списков слов, с которыми данная лексема используется в современном дискурсе, а также синтаксических моделей, списков слово- 
форм лексемы в определенных синтаксических конструкциях [Рублева, с. 62]. Например, в научном дискурсе сочетание have $+(\mathrm{mod})$ vi ew име- ет частотность 1700 , при этом наиболее частотной является форма have - 848 (см. рис.3).

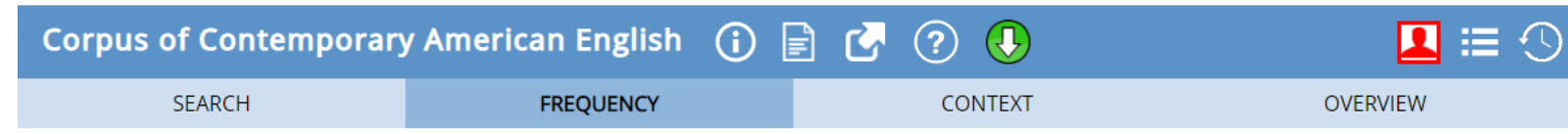

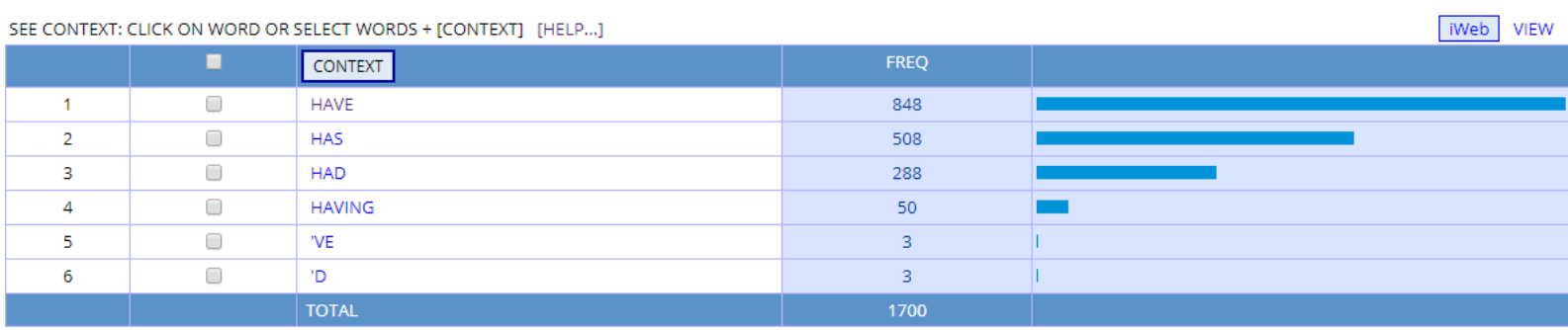

Рис. 3. Частотность глагольных форм модели V(mod) N (view) в научном дискурсе

В дискурсе художественной литературы сочетание have $+($ mod $)$ view имеет частотность
941 (см. рис. 4), при этом наиболее частотной является форма had - 485 фиксаций в COCA.

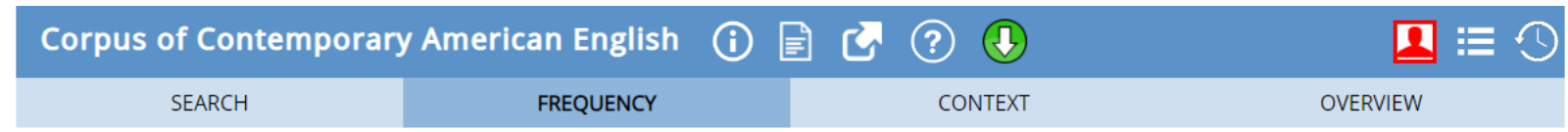

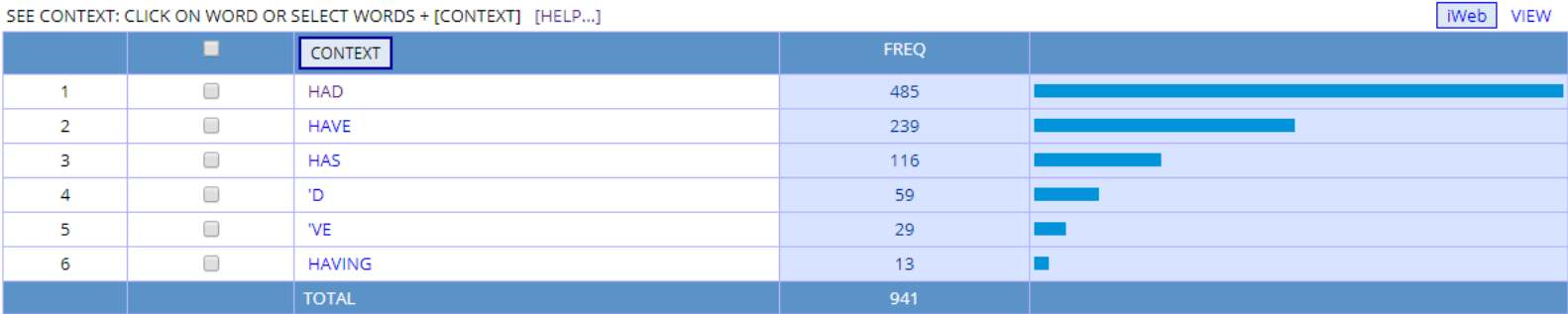

Рис. 4. Частотность глагольных форм модели V(mod) N (view) в дискурсе художественной литературы

\section{4. Выделение системных отномений.}

Все без исключения ЛСВ существительного view вступают в синонимические отношения с рядом существительных, демонстрируя таким образом широкую сеть системных отношений: ЛСВ 1: sight, perspective, field of vision, range of vision, vision, visibility, eyeshot; ЛСВ 2. outlook, prospect, panorama, vista, scene, aspect, perspective, spectacle, sight, scenery, landscape, seascape, riverscape, cityscape, townscape, snowscape, lookout; ЛСВ 3: opinion, point of view, viewpoint, belief, judgement [COCA].

Таким образом, в рамках корпусного подхода моделирование семантической структуры многозначного слова на основе дефиниционного анализа и дистрибутивного метода в настоящее время предполагает следующие этапы: отождествление слова, выделение перечня значений, лексико-семантический анализ ЛСВ, моделирование компонентного состава отдельных значений, моделирование внутрисистемных отношений изучаемого знака с другими языковыми знаками. Продемонстрированный алгоритм исследований осуществлен в целом ряде исследований автора и хорошо зарекомендовал себя как вполне надежный и валидный [Латыпова, Сиразеева, Шарифуллина, с. 93- 98]. К сожалению, ни один из существующих в настоящее время корпусов автоматически не снимает омонимию и полисемию, а дифференциация ЛСВ в рамках одной синтаксической модели и контекста осуществляется во всех случаях исследователем вручную. Данная проблема рассматривается как перспектива представленного научного исследования.

\section{Список литературы}

Арсеньева М. Г., Строева Т. В., Хазанович А. П. Многозначность и омонимия. Л.: Изд-во Лен. ун-та, 1966. $131 \mathrm{c}$.

Виноградов В. В. Русский язык. (Грамматическое учение о слове) / Под. ред. Г. А. Золотовой. 4-е изд. М.: Рус. Яз., 2001. 720 с.

Eфремова T. Ф. Толковый словарь словообразовательных единиц русского языка: ок. 1900 словообразов. единиц. 2-е изд., испр. М.:АСТ: Астрель, 2005. $636 \mathrm{c}$. 
Кацнельсон С. Д. Содержание слова, значение и обозначение. М. - Л.: Наука, 1965. 110 с.

Колианский Г. В. О природе контекста // Вопросы языкознания. М., 1959. № 4. С. 47-49.

Латыпова Л. А., Сиразеева А. Ф., Шарифуллина Э. А. Микроструктура двуязычного словаря активного типа. Филология и культура. Philology and Culture. 2016. №2 (44). С. 93-98.

Ольшанский И. Г. Лексическая полисемия и ее реализация в тексте // Науч. труды МГПИИЯ им. М. Тореза. М., 1983. Вып.217. С.67-75.

Ольшанский И. Г., Скиба В. П. Лексическая полисемия в системе языка и тексте. Кишинев: Штиинца, 1987. $128 \mathrm{c}$.

Рублева О. Л. Лексикология современного русского языка. Владивосток: ТИДОТ ДВГУ, 2004. 250 с

Стернин И. А., Саломатина М. С. Семантический анализ слова в контексте. Воронеж: «Истоки», 2011. $150 \mathrm{c}$.

Супрун А. Е., Плотников Б. А., Аладко Ж. С. К дистрибутивно-корреляционному изучению лексической семантики // Актуальные проблемы лексикологии: докл. второй лингвистической конфер. Новосибирск: Новосибирск. ун-т, 1969. С. 194-201.

Шмелев Д. Н. Основные типы семантических изменений в русском языке // Русский язык и советское общество. Лексика современного русского литературного языка. М.: Наука, 1968. 184 с.

Электронный каталог периодических изданий НБ THУ. URL: http://www.bigpi.biysk.ru/wwwsite/data/ typology/2.htm (дата обращения: 01.10.2019)

Ярцеева B. H. Лингвистический энциклопедический словарь / Гл. ред. В. Н. Ярцева. М.: Сов. энциклопедия, 1990. 685 с

Cambridge Advanced Learner's Dictionary and Thesaurus. URL: https:/dictionary.cambridge.org/dictionary/ (дата обращения: 01.10.2019).

Collins English Dictionary. URL: https://www.collinsdictionary.com/dictionary/english/ (дата обращения: 01.10.2019).

Corpus of Contemporary American English. URL: https://www.english-corpora.org/coca/ (дата обращения: 01.10.2019).

Marshall M.G. Systems at Risk: Violence, Diffusion, and Disintegration in the Middle East // Wars in the Midst of Peace: The International Politics of Ethnic Conflict / Ed. by David B. Carment, Patrick James. Pittsburg: University of Pittsburgh Press, 1997. 302p.

Oxford English Dictionary. URL: https://www.oed.com/ (дата обращения: 01.10.2019).

\section{References}

Arsenieva, M. G., Stroeva, T. V., Hazanovich, A. P. (1966). Mnogoznachnost' $i$ omonimiya [Polysemy and Homonymy]. 131 p. Leningrad, Leningrad State Univ. Press. (In Russian)

Cambridge Advanced Learner's Dictionary and Thesaurus. URL: https://dictionary.cambridge.org/dictionary/ (accessed: 01.10.2019). (In English)
Collins English Dictionary. URL: https:/www.collinsdictionary.com/dictionary/english/ (accessed: 01.10.2019). (In English)

Corpus of Contemporary American English. URL: https://www.english-corpora.org/coca/ (accessed: 01.10.2019). (In English)

Efremova, T. F. (2005). Tolkovyi slovar' slovoobrazovatel'nykh edinits russkogo iazyka [Explanatory Dictionary of the Russian Language Word Formation Units]. 636 p. Moscow, AST, Astrel. (In Russian)

Elektronnyi katalog periodicheskih izdanii NB TNU [Electronic Catalogue of Periodicals National Library of TNU]. URL: http://www.bigpi.biysk.ru/wwwsite/data/ typology/2.htm (accessed: 01.10.2019). (In Russian)

Iartseva, V. N. (1990). Lingvisticheskii entsiklopedicheskii slovar' [Linguistic Encyclopedic Dictionary]. 685 p. Moscow, Sov. entsiklopediia. (In Russian)

Katsnel'son, S. D. (1965). Soderzhanie slova, znachenie $i$ oboznachenie [Content of the Word, Its Meaning and Symbol]. 110 p. Moscow, Leningrad, Nauka. (In Russian)

Kolshanskii, G. V. (1959). O prirode konteksta [On the Nature of Context]. Voprosy iazykoznaniia = Issues of Linguistics. No. 4, pp. 47 - 53. (In Russian)

Latypova, L. A., Sirazeeva, A. F., Sharifullina, E. A. (2016) Mikrostruktura dvuiazychnogo slovaria aktivnogo tipa [An Entry in a Bilingual Dictionary of an Active Type]. Filologiya i kul'tura. Philology and Culture, No. 2 (44), pp. 93 - 98. (In Russian)

Marshall, M. G. (1997). Systems at Risk: Violence, Diffusion, and Disintegration in the Middle East Wars in the Midst of Peace: The International Politics of Ethnic Conflict. Ed. by David B. Carment, Patrick James. 302 p. Pittsburg, University of Pittsburgh Press. (In English)

Oxford English Dictionary. URL: https://www.oed.com/ (accessed: 01.10.2019). (In English)

Olshansky, I. G. (1983). Leksicheskaia polisemiia i ee realizatsiia $v$ tekste [Lexical Polysemy and Its Realization in Text]. 217 p. Scientific Works of Moscow Torez State Pedagogical Institute of Foreign Languages. (In Russian)

Olshansky, I. G., Skiba, V. P. (1987). Leksicheskaia polisemiia $v$ sisteme iazyka i tekste [Lexical Polysemy in Language System and Text]. 128 p. Kishinev, Shtiintsa. (In Russian)

Rubleva, O. L. (2004). Leksikologiia sovremennogo russkogo iazyka [Lexicology of the Contemporary Russian Language]. 250 p. Izdatelstvo Dalnevostochnogo universiteta. (In Russian)

Shmelev, D. N. (1968). Osnovnye tipy semanticheskih izmenenii $v$ russkom iazyke [The Main Types of Semantic Changes in the Russian Language]. Russkii iazyk I sovetskoe obshchestvo. 184 p. Moscow, Nauka. (In Russian)

Sternin, I. A., Salomatina, M. S. (2011). Semanticheskii analiz slova v kontekste [Semantic Analysis of Words in Context]. 150 p. Voronezh, Istoki. (In Russian)

Suprun, A. E., Plotnikov, B. A., Aladko, Zh. S. (1969). K distributivno-korrelyacionnomu izucheniyu leksicheskoj semantiki [On the Distributive-Correlation Study of Lexical Semantics]. Pp. 194 - 201. Novosibirsk, Novosibirsrii un-t. (In Russian) 
Vinogradov, V. V. (2001). Russkii Language (Grammatical Studies of the Word)]. 720 p. iazyk.(Grammaticheskoe uchenie o slove) [The Russian Moscow, Russkii iazyk. (In Russian)

The article was submitted on 08.11.2019

Поступила в редакцию 08.11.2019

Шарифуллина Эльвира Альбертовна, ассистент,

Казанский федеральный университет, 420008, Россия, Казань,

Кремлевская, 18.

ehvi-ehvi12@rambler.ru

\section{Sharifullina Elvira Albertovna,}

Assistant Professor,

Kazan Federal University,

18 Kremlyovskaya Str.,

Kazan, 420008, Russian Federation.

ehvi-ehvi12@rambler.ru 